\title{
No more "9 to 5"
}

Written by: Balázs Gyimesi, OECD Observer

Last update: 28 January 2020

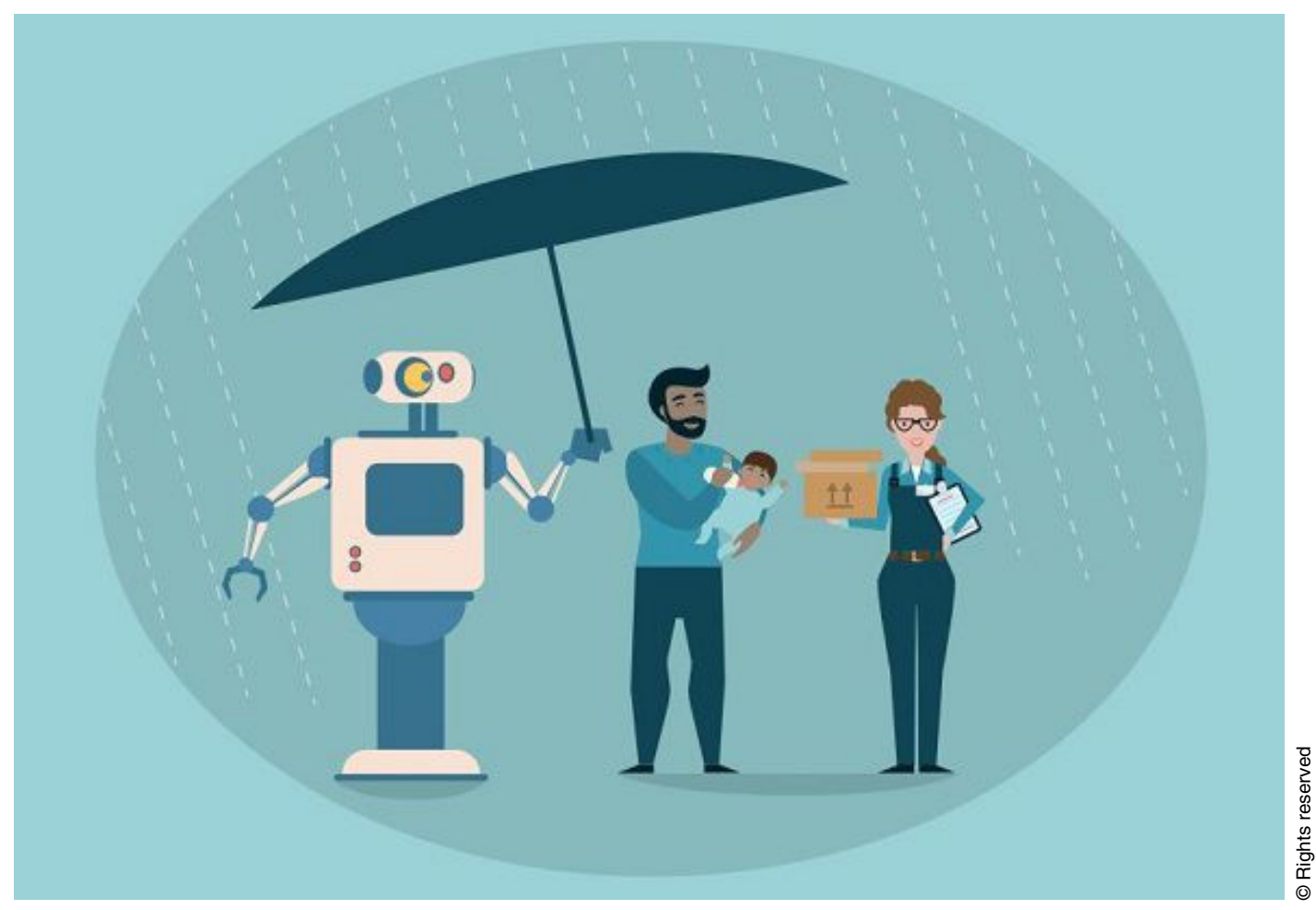

No more "9 to 5 " I Illustration for No more "9 to 5 "

"Workin' 9 to 5; What a way to make a living", Dolly Parton sang in her classic hit. The year was 1980, and Parton's character in the eponymous film, 9 to 5, already pioneered numerous policies of the new world of work to come, such as flexible work hours and a job-sharing programme. Some of these changes have since become widespread in certain countries and industries. And they affect social protection policies, too, as the OECD report The Future of Social Protection: What Works for Non-standard Workers? shows.

Most social protection systems were designed with the archetypical full-time, " 9 to 5" employee in mind. But with internet platform-based "gig" economy on the rise, coverage gaps become apparent. Across the OECD on average, $16 \%$ of all workers are self-employed, and a further $13 \%$ of all employees are on temporary 
employment contracts. Many of them earn low wages, and face frequent unemployment spells. None of this does their pension prospects any good either. Governments have realised this and launched reforms to improve the situation of such workers.

Take Italy, where self-employed workers who are economically dependent on a single or very few clients, so-called "para-subordinates", made up around $16 \%$ of new workers in 2008. In effect, these self-employed workers are employees, but without receiving the same contract and benefits, yet many remain in these jobs for several years. Italian para-subordinate workers are well educated on average, with $47 \%$ having tertiary education. Thanks to government reforms, the number of para-subordinate workers has declined since 2008. The strategy included gradual increases in contribution rates, abolition of certain types of contractual agreements, and reducing the advantage to employers of para-subordinate agreements.

In the new world of work, such new policies can help ensure better lives, even for workers whose contract does not say "9 to 5".

\section{References}

OECD (2018), The Future of Social Protection: What Works for Non-standard Workers?, OECD Publishing, Paris, https://doi.org/10.1787/9789264306943-en http://dx.doi.org/10.1787/9789264306943 